\title{
Effects of Addition of Arginine, Cystine, and Glycine to the Bovine Milk-Simulated Amino Acid Mixture on the Level of Plasma and Liver Cholesterol in Rats
}

\author{
Kazuhito YoshidA, Masatoshi YAHIRo, and Kenkichi AHIKO ${ }^{1}$ \\ Technical Research Institute, Snow Brand Milk Products Co., Ltd., \\ Minamidai, Kawagoe, Saitama 350, Japan
}

(Received May 2, 1988)

\begin{abstract}
Summary The effects of the addition of varying levels of arginine (Arg), cystine (Cys), and glycine (Gly) to the bovine milk-simulated amino acid mixture on the levels of plasma and liver cholesterol were investigated in rats. The diets containing a high amount of Cys lowered significantly the level of plasma cholesterol as the amount of Cys in diets increased. The serum high density lipoprotein (HDL)-cholesterol level and fecal excretion of acidic steroids were higher in rats fed the Cys diets than in those fed the Arg and Gly diets. No difference, however, was observed in the content of liver cholesterol. Liver triglyceride contents elevated significantly on feeding the Arg and Cys diets. Furthermore, liver phospholipid contents elevated significantly on feeding the Arg diet but lowered on feeding the Cys diet. Therefore, these results indicated that the feeding of a high amount of Cys lowers the plasma cholesterol levels as the result of the enhanced conversion of cholesterol to bile acids.
\end{abstract}

Key Words cholesterol metabolism, milk protein, amino acid mixture, arginine, cystine, glycine, serum lipids, liver lipids, fecal neutral steroids, fecal acidic steroids

Since the report of Carroll and Hamilton (1), a number of studies have been published on the effect of dietary protein on the plasma cholesterol level (2-6). It has been reported that soybean protein rather than casein lowers the level of plasma cholesterol $(1,2)$. The mechanism which results in the low plasma cholesterol levels with dietary proteins remains controversial but various hypotheses have been proposed, including the difference in the amino acid composition(3), dietary arginine/lysine ratios (2), the amount and type of sulfur amino acids (4), and the difference in protein absorption $(5,6)$. However, none of these hypotheses can fully explain the observed relationship between the plasma cholesterol level and dietary proteins. We hypothesized that the difference in plasma cholesterol levels between

1 吉田一仁, 八尋政利, 阿彦健吉 
casein and soybean protein might be attributed to the different amino acid compositions, especially Arg, Cys, and Gly, of these proteins. Therefore, it is of importance to elucidate the role of these amino acids in plasma cholesterol levels. In the present study, we have examined the effects of Arg, Cys, and Gly on cholesterol metabolism in order to assess the effect of the addition of these amino acids to the amino acid mixture simulated to bovine milk protein in rats.

\section{EXPERIMENTAL}

Animals and diets. Male Sprague-Dawley rats weighing approximately 120 $150 \mathrm{~g}$ (4 weeks, Japan Clea Co., Tokyo) were used. Animals were fed a commercial diet (type CE-2, Japan Clea Co., Tokyo) for 1 week after arrival and then fed ad libitum each experimental diet for 29 days (Table 1). Body weight gain and diets consumed were recorded every day during experiments. The eight modified experimental diets containing different amounts of Arg, Cys, and Gly were formulated. The composition is given in Table 2. Since it is known that the total amount of proteins in diets affects the plasma cholesterol level(7), amino acids except Arg, Cys, and Gly in each group were reduced proportionally to adjust the total amino acid levels to $20 \%$. At the end of the experiment, animals were fasted for $18 \mathrm{~h}$ and sacrificed under anesthetization with ether.

Sample preparation. On days 5, 12, 19, and 29 after feeding the experimental diets, blood was withdrawn from the tail vein using a heparin-coated hematocrit tube (Drummond Co., Broomall, Pa.) and blood plasma was harvested after centrifugation at 3,000 rpm for $15 \mathrm{~min}$. At the end of the experiment, blood was withdrawn from the vena cava posterior and blood serum was separated by centrifugation at 3,000 rpm for $15 \mathrm{~min}$. Livers were excised, rinsed with saline and then lyophilized. Feces were collected for 2 days (days 11 to 12, and days 25 to 26) and lyphilized.

Table 1. Diet composition $(\%)$.

\begin{tabular}{lc}
\hline Amino acid mixture & 20 \\
Vitamin mixture $^{1}$ & 1 \\
Mineral mixture $^{1}$ & 5 \\
Lard & 15 \\
Corn oil & 2 \\
Cholesterol & 1 \\
Sodium cholate & 0.25 \\
Cellulose $^{2}$ & 3 \\
Choline chloride $_{\text {Sucrose }}$ & 0.2 \\
Corn starch & 40 \\
\hline
\end{tabular}

\footnotetext{
${ }^{1}$ AIN-76 mixture. ${ }^{2}$ Avicel from Merck Co., Darmstadt.
} 
Table 2. Composition of dietary amino acid mixture in the experimental diets $(\mathrm{mg} / 100 \mathrm{~g})$.

\begin{tabular}{|c|c|c|c|c|c|c|c|c|}
\hline \multirow{2}{*}{ Amino acid } & \multicolumn{8}{|c|}{ Group } \\
\hline & $\mathrm{A}^{1}$ & B & $\mathrm{C}$ & $\mathrm{D}$ & $\mathrm{E}$ & $\mathrm{F}$ & G & $\mathrm{H}$ \\
\hline Arg & 552 & 552 & 552 & 552 & $3,040^{2}$ & $3,040^{2}$ & $3,040^{2}$ & $3,040^{2}$ \\
\hline Cys & 154 & 154 & $844^{3}$ & $844^{3}$ & 154 & 154 & $844^{3}$ & $844^{3}$ \\
\hline Gly & 368 & $1,684^{4}$ & 368 & $1,684^{4}$ & 368 & $1,684^{4}$ & 368 & $1,684^{4}$ \\
\hline Ile & 982 & 914 & 946 & 878 & 853 & 785 & 817 & 749 \\
\hline Leu & 1,814 & 1,688 & 1,748 & 1,622 & 1,576 & 1,449 & 1,509 & 1,383 \\
\hline Phe & 860 & 800 & 829 & 769 & 747 & 687 & 716 & 656 \\
\hline Tyr & 1,074 & 999 & 1,035 & 960 & 933 & 858 & 894 & 819 \\
\hline Thr & 830 & 772 & 800 & 742 & 721 & 663 & 691 & 633 \\
\hline Trp & 282 & 262 & 272 & 252 & 245 & 225 & 235 & 215 \\
\hline Val & 1,260 & 1,172 & 1,214 & 1,126 & 1,094 & 1,007 & 1,048 & 961 \\
\hline His & 492 & 458 & 474 & 440 & 427 & 393 & 409 & 375 \\
\hline Ala & 644 & 599 & 621 & 576 & 559 & 515 & 536 & 491 \\
\hline Asp & 1,598 & 1,487 & 1,540 & 1,429 & 1,388 & 1,277 & 1,330 & 1,219 \\
\hline Glu & 4,300 & 4,002 & 4,142 & 3,844 & 3,734 & 3,435 & 3,578 & 3,278 \\
\hline Pro & 1,812 & 1,686 & 1,746 & 1,620 & 1,574 & 1,448 & 1,508 & 1,382 \\
\hline Ser & 1,044 & 971 & 1,006 & 933 & 907 & 834 & 869 & 796 \\
\hline Lys & 1,474 & 1,372 & 1,420 & 1,318 & 1,280 & 1,178 & 1,226 & 1,124 \\
\hline Met & 460 & 428 & 443 & 411 & 400 & 328 & 383 & 351 \\
\hline Total & 20,000 & 20,000 & 20,000 & 20,000 & 20,000 & 20,000 & 20,000 & 20,000 \\
\hline
\end{tabular}

Amino acid mixture content is $20 \%$ of the diet. ${ }^{1}$ Equal to amino acid composition of bovine milk protein. ${ }^{2}$ Twice the level of arginine in isolated soy protein. ${ }^{3}$ Twice the level of cystine in whey protein concentrate. ${ }^{4}$ Twice the level of glycine in isolated soy protein.

Analytical methods. Plasma and serum total cholesterol, triglyceride (TG), and phospholipid (PL) were measured enzymatically using commercially available kits (Detamina TC-5, Detamina TG, and Detamina PL, respectively, Kyowa Medics Co., Tokyo), as described by Shibuya et al.(8). Serum high density lipoprotein cholesterol (HDL-chol) was determined by the enzymatic method using a commercial kit (Detamina TC-5)(8). Total lipids from the dried livers were extracted and purified according to the method of Folch et al. (9) and dissolved in isopropanol. After addition of $20 \%$ solution of polyoxyethylene octylphenylether (Toritone, Wako Pure Chemical Co., Osaka), liver cholesterol, TG, and PL were assayed by the methods described above for plasma lipids. Fecal neutral steroids from the dried feces were extracted using the method described for liver lipids and then purified lipids were dissolved in chloroform. Gas-liquid chromatography 
(model, Shimadzu GL mini: silicone GS-17, $2.1 \mathrm{~m}$ ) was performed to measure the content of neutral steroids. According to the method of Okutsu and Hasegawa (10), fecal acidic steroids from freeze-dried feces were extracted three times with ethanol at $75^{\circ} \mathrm{C}$ and then lyophilized. After they were dissolved with dilute methanol $(3 \%)$, fecal acidic steroids were determined enzymatically (Enzabile: Daiichi Chemical Co., Tokyo).

Statistical analysis. Experimental data were analyzed statistically by a oneway and factorial analysis of variances. When $F$-test was significant, comparisons were made using the Tukey's procedure to determine which pairs of means were significantly different at $p<0.05$.

\section{RESULTS AND DISCUSSION}

Table 3 summarizes body weight gain, food intake, and liver weight of rats during 29 days of feeding. No difference was observed in the body weight gain and liver weight among the groups studied. There was, however, a significant increase in food intake in rats fed the F (Arg, Gly) diet compared with those fed the C (Cys) and D (Cys, Gly) diets.

Figure 1 illustrates the plasma cholesterol levels on feeding of the amino acid mixture diets for $5,12,19$, and 29 days. No significant difference was observed in the plasma cholesterol levels among groups fed the diets for 5 days. In contrast, the plasma cholesterol levels at 12 days of feeding were lowered significantly in rats fed the C (Cys), D (Cys, Gly), G (Arg, Cys), and H (Arg, Cys, Gly) diets compared to those in rats fed the $\mathrm{A}$ (milk protein) diet. The significant differences, however, were not observed on days 19 and 29. The effect of Arg, Cys, and Gly on plasma cholesterol levels was compared by factorial analysis and the results are shown in

Table 3. Effects of amino acid mixture feeding on body weight gain, food intake, and liver weight.

\begin{tabular}{cccc}
\hline Group & $\begin{array}{c}\text { Body wt. gain } \\
(\mathrm{g} / 29 \text { days })\end{array}$ & $\begin{array}{c}\text { Food intake } \\
(\mathrm{g} / \text { day })\end{array}$ & $\begin{array}{c}\text { Liver weight } \\
(\% \text { of body wt. })\end{array}$ \\
\hline A & $157 \pm 5$ & $17.4 \pm 0.2$ & $2.3 \pm 0.1$ \\
B & $157 \pm 6$ & $17.0 \pm 0.5$ & $2.3 \pm 0.1$ \\
C & $149 \pm 5$ & $16.6 \pm 0.5^{\mathrm{a}}$ & $2.3 \pm 0.1$ \\
D & $156 \pm 4$ & $16.5 \pm 0.3^{\mathrm{b}}$ & $2.2 \pm 0.1$ \\
E & $164 \pm 8$ & $17.6 \pm 0.5$ & $2.4 \pm 0.1$ \\
F & $164 \pm 4$ & $18.4 \pm 0.2^{\mathrm{ab}}$ & $2.3 \pm 0.1$ \\
G & $169 \pm 6$ & $17.4 \pm 0.2$ & $2.3 \pm 0.1$ \\
H & $153 \pm 7$ & $17.1 \pm 0.5$ & $2.3 \pm 0.1$ \\
\hline
\end{tabular}

Results are expressed as mean values $\pm \mathrm{SE}$ for 8 rats. Values in a column sharing the same superscript letter are significantly different at $p<0.05$. Feeding period, 29 days. Initial body weight, $134 \pm 3.7 \mathrm{~g}$. 


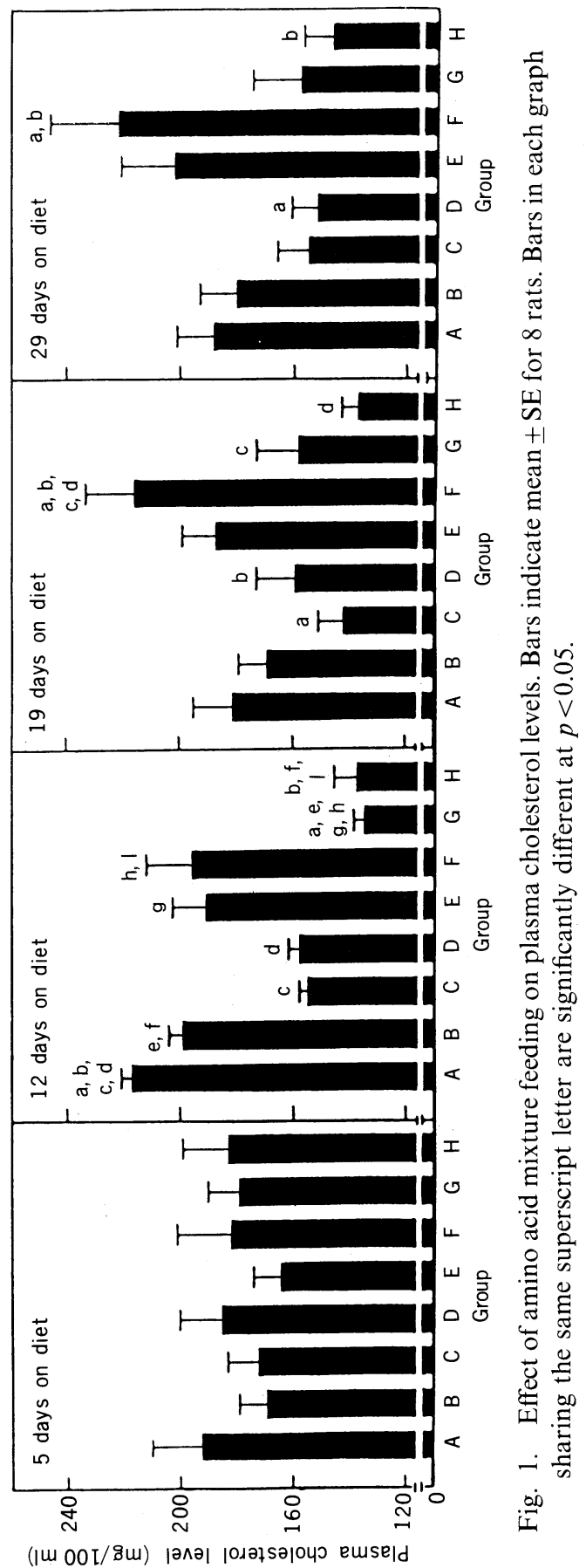


Table 4. Effect of arginine, cystine, and glycine on plasma cholesterol level.

\begin{tabular}{lcccc}
\hline & \multicolumn{5}{c}{ Days on diet } \\
\cline { 2 - 5 } Source & 5 & 12 & 19 & 29 \\
\hline (Main effects) & $F$ & $F$ & $F$ & $F$ \\
Arginine & 0.17 & 3.15 & 1.46 & 1.70 \\
Cystine & 0.02 & $38.52^{* *}$ & $18.86^{* *}$ & $16.99^{* *}$ \\
Glycine & 0.01 & 0.00 & 0.11 & 0.00 \\
\hline
\end{tabular}

$F$ values represent factorial analysis of variance. Significant difference between dietary treatment, ${ }^{* *} p<0.01$.

Table 4. The $F$ value of the main effects of Cys was statistically significant on the days 12, 19, and 29. However, the $F$ values of the main effects of Arg and Gly and the interactions among the amino acids were not statistically significant. Therefore, it was found that the diets containing the high amount of Cys (2-fold higher than that of whey protein) are correlated to the low level of plasma cholesterol, which is in agreement with the finding by Sugiyama and Muramatsu(11). However, we did not observe a significant decrease in the plasma cholesterol level on feeding the Gly diet.

It has been reported that dietary Cys elevates the concentration of taurine in plasma and liver and increases urinary excretion of taurine (11). It has also been demonstrated that dietary taurine decreases the plasma level of cholesterol in experimental animals as well as humans (12), and causes the reduction of the biliary Gly/taurine ratios and a decrease in the plasma cholesterol level(13). In the present experiment, the plasma level of taurine was $1.94 \pm 0.44,2.17 \pm 0.61,4.51 \pm 1.61$, $2.04 \pm 0.32$, and $5.12 \pm 1.30 \mathrm{mg} / \mathrm{dl}$ in rats fed the $\mathrm{A}, \mathrm{B}, \mathrm{D}, \mathrm{E}$, and $\mathrm{H}$ diets, respectively. Therefore, addition of the high level of Cys increased the plasma level of taurine and consequently resulted in decreases in plasma cholesterol levels. On the other hand it is known that feeding of high methionine (Met) diets causes a significant elevation of plasma cholesterol level. Sugiyama et al. (14) reported that the dietary methyl compounds such as Met, choline, and betaine elevate the plasma cholesterol level but the intermediary metabolites of Met such as homocystine and cysteine lower it. This suggested that the methyl group in these compounds was largely attributable to the difference in the plasma cholesterol level between Cys and Met feeding.

Table 5 shows the fasting serum lipid levels. Total cholesterol, TG, and PL levels were not influenced by the supplemented amino acids. On the other hand, rats given $\mathrm{E}$ and $\mathrm{F}$ diets gave lower levels of serum HDL-cholesterol than those given $\mathrm{C}$ and $\mathrm{D}$ diets even though the former groups showed high levels of plasma cholesterol on day 29.

Table 6 shows the concentration of liver lipids. Rats fed the E diet showed an increase in the phospholipid content without a significant change in the liver 
Table 5. Effects of amino acid mixture feeding on fasting serum lipids.

\begin{tabular}{crcrr}
\hline Group & $\begin{array}{r}\text { Total-chol. } \\
(\mathrm{mg} / 100 \mathrm{ml})\end{array}$ & $\begin{array}{c}\text { HDL-chol. } \\
(\mathrm{mg} / 100 \mathrm{ml})\end{array}$ & $\begin{array}{r}\text { Triglyceride } \\
(\mathrm{mg} / 100 \mathrm{ml})\end{array}$ & $\begin{array}{r}\text { Phospholipid } \\
(\mathrm{mg} / 100 \mathrm{ml})\end{array}$ \\
\hline $\mathrm{A}$ & $121.9 \pm 23.5$ & $12.4 \pm 1.1$ & $120.9 \pm 26.1$ & $110.3 \pm 14.3$ \\
$\mathrm{~B}$ & $96.4 \pm 7.6$ & $11.4 \pm 0.8$ & $69.0 \pm 8.6$ & $81.3 \pm 4.5$ \\
$\mathrm{C}$ & $103.6 \pm 23.8$ & $14.5 \pm 1.2^{\mathrm{ab}}$ & $69.2 \pm 9.9$ & $85.9 \pm 9.4$ \\
$\mathrm{D}$ & $72.1 \pm 6.7$ & $15.1 \pm 10^{\mathrm{cd}}$ & $72.9 \pm 8.5$ & $91.4 \pm 5.9$ \\
$\mathrm{E}$ & $132.1 \pm 31.7$ & $9.6 \pm 1.2^{\mathrm{ac}}$ & $78.1 \pm 5.8$ & $96.8 \pm 10.6$ \\
$\mathrm{~F}$ & $189.1 \pm 46.8$ & $9.8 \pm 0.4^{\mathrm{bd}}$ & $91.8 \pm 14.7$ & $107.8 \pm 12.5$ \\
$\mathrm{G}$ & $111.3 \pm 19.0$ & $11.3 \pm 1.0$ & $70.8 \pm 10.4$ & $99.2 \pm 5.8$ \\
$\mathrm{H}$ & $117.3 \pm 14.7$ & $12.2 \pm 0.6$ & $81.2 \pm 12.1$ & $99.7 \pm 9.3$ \\
\hline
\end{tabular}

Results are expressed as mean values \pm SE for 8 rats. Values in a column sharing the same superscript letter are significantly different at $p<0.05$.

Table 6. Effects of amino acid mixture feeding on liver lipids.

\begin{tabular}{cccc}
\hline Group & $\begin{array}{c}\text { Cholesterol } \\
(\mathrm{mg} / \mathrm{g})\end{array}$ & $\begin{array}{c}\text { Triglyceride } \\
(\mathrm{mg} / \mathrm{g})\end{array}$ & $\begin{array}{c}\text { Phospholipid } \\
(\mathrm{mg} / \mathrm{g})\end{array}$ \\
\hline A & $156.3 \pm 6.2$ & $141.9 \pm 15.2$ & $63.5 \pm 3.2^{\mathrm{a}}$ \\
B & $156.8 \pm 3.6$ & $123.4 \pm 9.3^{\mathrm{a}}$ & $60.2 \pm 1.7^{\mathrm{bc}}$ \\
C & $146.9 \pm 3.2$ & $135.3 \pm 7.8$ & $58.4 \pm 0.8^{\mathrm{def}}$ \\
D & $156.6 \pm 8.2$ & $149.9 \pm 11.5$ & $57.3 \pm 2.0^{\mathrm{ghi}}$ \\
E & $164.3 \pm 8.3$ & $129.6 \pm 10.4^{\mathrm{b}}$ & $77.6 \pm 4.3^{\mathrm{abdg}}$ \\
F & $165.1 \pm 5.0$ & $131.2 \pm 9.3^{\mathrm{c}}$ & $72.6 \pm 3.2^{\mathrm{ceh}}$ \\
G & $149.8 \pm 6.5$ & $182.3 \pm 20.7$ & $70.7 \pm 3.2^{\mathrm{fi}}$ \\
H & $151.3 \pm 5.5$ & $191.8 \pm 17.6^{\mathrm{abc}}$ & $65.9 \pm 3.2$ \\
\hline
\end{tabular}

Results are expressed as mean values \pm SE for 8 rats. Values in a column sharing the same superscript letter are significantly different at $p<0.05$.

cholesterol content compared with the A diet. The groups given $\mathrm{G}$ and $\mathrm{H}$ diets tended to show an increase in the level of liver TG compared with the A diet. The effect of the addition of Arg, Cys, and Gly on liver cholesterol, TG, and PL contents were compared by factorial analysis and the results are shown in Table 7 . We observed that the $F$ values of the main effects of Arg and Cys were statistically significant in the content of liver TG. It turned out that addition of both amino acids increased the liver TG content. The statistically significant $F$ values for the main effects of Arg and Cys and the interaction between the addition of both amino acids were observed in the liver PL content. The addition of Arg increased the content of liver PL whereas Cys decreased it. Furthermore, no statistically significance in liver lipids was observed in the Gly diets. It has been reported by Yagasaki et al.(15) that liver TG and cholesterol contents are increased by the 
Table 7. Effect of arginine, cystine, and glycine on liver lipids.

\begin{tabular}{lccc}
\hline & \multicolumn{3}{c}{ Parameter analyzed } \\
\cline { 2 - 4 } Source & Cholesterol & Triglyceride & Phospholipid \\
\hline (Main effects) & $F$ & $F$ & $F$ \\
Arginine & 0.61 & $4.92^{*}$ & $34.19^{* *}$ \\
Cystine & 5.22 & $12.20^{* *}$ & $7.00^{*}$ \\
Glycine & 0.49 & 0.04 & 0.47 \\
\hline
\end{tabular}

$F$ values represent factorial analysis of variance. Significant difference between dietary treatment: ${ }^{*} p<0.05,{ }^{* *} p<0.01$.
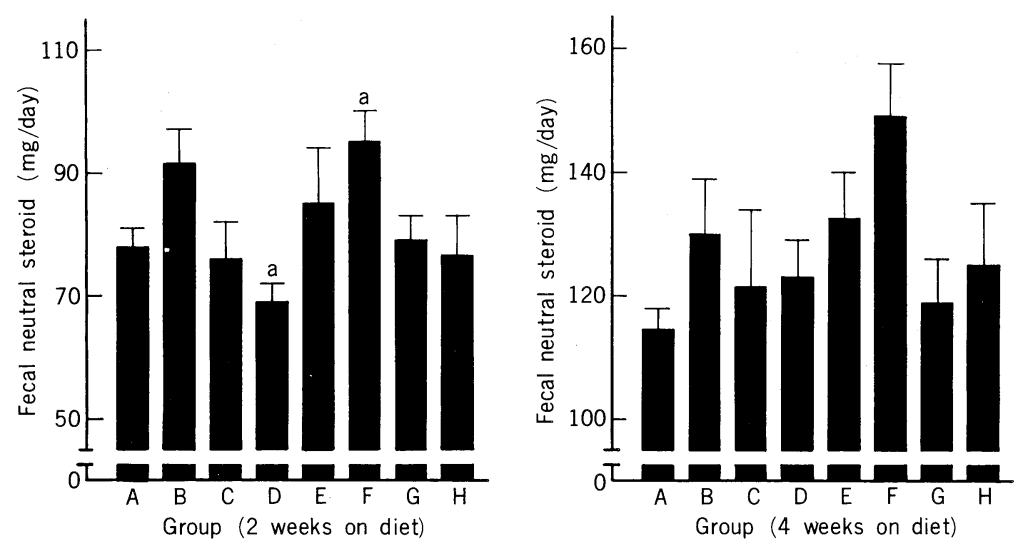

Fig. 2. Effect of amino acid mixture feeding on fecal neutral steroid. Bars indicate mean $\pm \mathrm{SE}$ for 8 rats. Bars in each graph sharing the same superscript letter are significantly different at $p<0.05$.

addition of $1.2 \%$ Cys to the $20 \%$ casein diet. In contrast, Tsuji et al. (16) showed that $4 \%$ Cys added to the $22 \%$ casein diet reduced the content of liver cholesterol. These observations suggest that the effect of addition of the amino acid mixture could be influenced by the amount of amino acids supplemented since our results do not support their observations $(15,16)$.

Figure 2 represents the amount of fecal neutral steroids excreted. A significant difference was observed only in rats fed D and F diets for 2 weeks. No significant difference, however, was observed among the groups studied for 4 weeks although the amount of fecal neutral steroids excreted increased. The reason for the significant difference is not known.

Figure 3 represents the effect of the amino acid mixture on fecal excretion of acidic steroids. The rats given $\mathrm{C}, \mathrm{G}$, and $\mathrm{H}$ diets for 2 and 4 weeks and those given the $\mathrm{D}$ diet for 4 weeks showed a trend toward increasing fecal acidic steroids. On the contrary, as shown in the Fig. 1, the elevation of plasma cholesterol was suppressed 

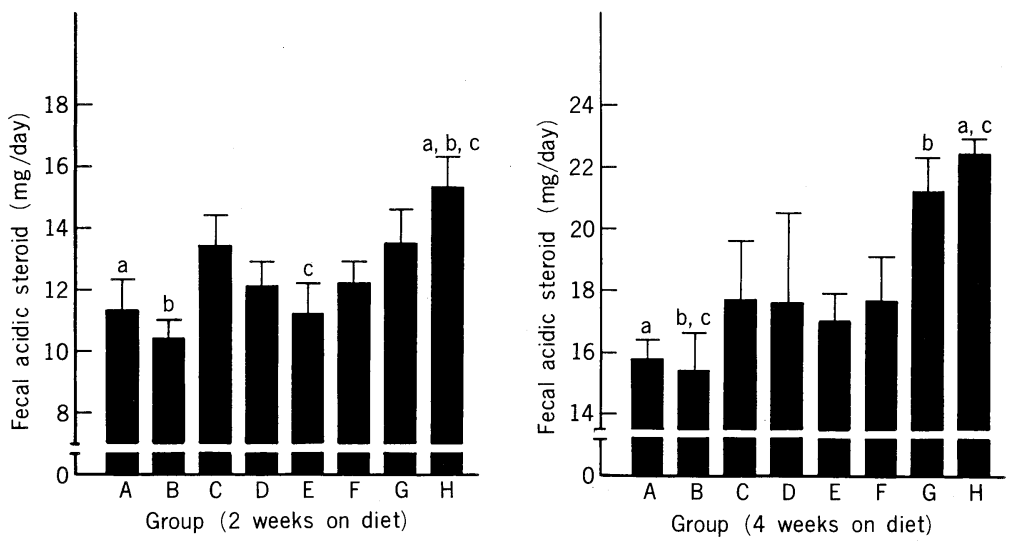

Fig. 3. Effect of amino acid mixture feeding on fecal acidic steroid. Bars indicate mean \pm SE for 8 rats. Bars in each graph sharing the same superscript letter are significantly different at $p<0.05$.

without changing the liver cholesterol content in these groups. These results indicate that addition of Cys (or taurine) stimulates metabolism of cholesterol, resulting in an increased formation of bile acids and, hence, a reduction of plasma cholesterol levels. Sautier et al. (17) reported that whey protein causes a decrease in the plasma cholesterol level accompanying an increase in fecal acidic steroid excretion compared with that of casein. Since the content of Cys in whey protein was $2.21 \%$ of total amino acids compared to $0.36 \%$ in casein, it is most likely that the increment of the Cys content in whey protein causes the lowered plasma cholesterol levels.

\section{REFERENCES}

1) Carroll, K. K., and Hamilton, R. M. J. (1975): Effects of dietary protein and carbohydrate on plasma cholesterol levels in relation to atherosclerosis. J. Food. Sci., 40, 18-23.

2) Kritchevsky, D. (1979): Vegetable protein and atherosclerosis. J. Am. Oil Chem. Soc., 56, 135-140.

3) Huff, M. W., and Carroll, K. K. (1980): Effects of dietary proteins and amino acid mixtures on plasma cholesterol levels in rabbits. J. Nutr., 110, 1676-1685.

4) Sugiyama, K., Kushima, Y., and Muramatsu, K. (1984): Effects of methionine, cystine and taurine on plasma cholesterol level in rats fed a high cholesterol diet. Agric. Biol. Chem., 48, 2897-2899.

5) Doi, K., Iwami, K., Ibuki, F., and Kanamori, M. (1986): Effect of feeding peptic digest of soy protein isolate on rat serum cholesterol. J. Nutr. Sci. Vitaminol., 32, 373-379.

6) Imai, K., Sakakibara, K., and Ibuki, F. (1986): Involvement of post-digestion "hydrophobic" peptides in plasma cholesterol-lowering effect of dietary plant proteins. Agric. Biol. Chem., 50, 1217-1222.

7) Tsuji, K., Ichikawa, T., Kawamura, M., Nakagawa, Y., and Inomata, M. (1985): Effects of methionine supplement to casein diets on cholesterol metabolism in several

Vol. 34, No. 6, 1988 
strains of rat. Sulfur Amino acids, 8, 489-498.

8) Shibuya, K., Suzukawa, N., Okutsu, S., and Hasegawa, K. (1982): Influence of a shortterm feeding of isocaloric replacement of dietary oils with different fatty acid composition on plasma lipid levels in young adult women. Joshi Eiyou Daigaku Kiyou (in Japanese), 13, 19-33.

9) Folch, J., Lee, M., and Stanley, G. H. S. (1957): A simple method for the isolation and purification of total lipids from animal tissues. J. Biol. Chem., 226, 497-509.

10) Okutsu, S., and Hasegawa, K. (1981): The effects of dietary factors on lipid levels and fecal bile acid pattern in rats. Joshi Eiyou Daigaku Kiyou (in Japanese), 12, 65-76.

11) Sugiyama, K., and Muramatsu, K. (1985): Relationship between amino acid composition of diet and plasma cholesterol level in rats. Rep. Res. Commum. Essent. Amino Acids (Tokyo), No. 106, 23-27.

12) Murakami, T., Matsuura, C., Ujiki, M., Takada, H., Miyoshi, S., Kajiyama, G., Mizuno, T., Inoue, M., Asakura, Y., and Tsunoda, Y. (1973): A clinical study on the influence of taurine on hyperlipemia. Kiso to Rinsho (in Japanese), 7, 146-150.

13) Burns, M. J., and Self, K. S. (1969): Effects of cystine, niacin and taurine on cholesterol and bile acid metabolism in rabbits. Metabolism, 18, 427-432.

14) Sugiyama, K., Akai, H., and Muramatsu, K. (1986): Effects of methionine and related compounds on plasma cholesterol level in rats fed a high cholesterol diet. J. Nutr. Sci. Vitaminol., 32, 537-549.

15) Yagasaki, K., Machida, M., and Funabiki, K. (1986): Effects of dietary methionine, cystine, and glycine on endogenous hypercholesterolemia in hepatoma-bearing rats. $J$. Nutr. Sci. Vitaminol., 32, 643-651.

16) Tsuji, K., Seki, Y., and Iwao, H. (1979): Cholesterol-lowering effects of taurine and sulfur-containing amino acids in serum and liver of rats. Sulfur-containing Amino Acids, 2, 143-154.

17) Sautier, C., Dieng, K., Flament, C., Doucet, S., Suquet, J. P., and Lemonnier, D. (1983): Effects of whey protein, casein, soya-bean and sunflower proteins on the serum, tissue and faecal steroids in rats. Br. J. Nutr., 49, 313-319. 